\title{
O LIVRO DAS PASSAGENS E O CONCEITO DE IMAGEM DIALÉTICA EM WALTER BENJAMIN
}

\author{
Claudio Celso Alano da Cruz ${ }^{21}$
}

Resumo: O presente artigo, utilizando-se das conhecidas "teses" benjaminianas sobre a história, busca estabelecer alguns caminhos possíveis para uma melhor compreensão do conceito de imagem dialética, desenvolvido por Benjamin no Livro das Passagens, especialmente na parte da obra que chamou de Arquivo N (Konvolut N), tendo em vista sua utilização em futuras pesquisas que tenham como suporte teórico a filosofia da história de Walter Benjamin.

Palavras-chave: imagem dialética; constelação; Livro das Passagens; Teses sobre o conceito da história; Walter Benjamin.

Resumen: El presente artículo, tomando las conocidas "tesis" benjaminianas a respecto de la historia, tiene por meta establecer caminos posibles para una mejor comprensión del concepto de imagen dialéctica, desarrollado por Benjamin en el Libro de las Pasajes, muy especialmente en su apartado Archivo N (Konvolut N), en la perspectiva de su utilización en futuras investigaciones que tengan como fundamento teórico la filosofía de la historia de Walter Benjamin.

Palabras-chave: imagen dialéctica; constelación; Libro de las Pasajes; Teses sobre el concepto de la historia; Walter Benjamin.

1.

O Livro das Passagens (Passagen-Werk) ${ }^{22}$, de Walter Benjamin, elaborado entre 1927 e 1940, compõe-se de exatos 4.234 fragmentos,

${ }^{21}$ Doutor em Teoria Literária. Professor Associado da Universidade Federal de Santa Catarina (UFSC) e Bolsista de Produtividade em Pesquisa do Conselho Nacional de Pesquisa Científica (CNPq). Realizou Pós-Doutoramento na Universidad de Buenos Aires (UBA).

22 BENJAMIN, Walter. Passagens. Organização: Willi Bolle. Colaboração: Olgária Chain Féres Matos. São Paulo/Belo Horizonte: Ed.UFMG/Imprensa Oficial do Estado de São Paulo, 2006. 
distribuídos por 36 arquivos temáticos, dispostos de $\mathrm{A}$ a $\mathrm{Z}$, numa primeira parte, e de "a" a "z", em uma segunda parte, sendo que nessa vários arquivos ainda estavam "vazios", esperando por materiais que jamais ali chegariam, já que seu autor, como se sabe, optaria pelo suicídio em 1940, evitando assim cair nas mãos dos nazistas. Benjamin reservou o arquivo $\mathrm{N}$ (Konvolut N), intitulado "Teoria do Conhecimento, Teoria do Progresso", para explicitar o conceito de imagem dialética - noção central dessa que vem sendo considerada uma das mais importantes obras teóricas do século XX -, conceito esse que será também de grande importância para o entendimento das suas já célebres "Teses sobre o conceito da história". O presente artigo procura estabelecer alguns caminhos possíveis para uma melhor compreensão do referido conceito, tendo em vista sua utilização em futuras pesquisas que tenham como suporte teórico a filosofia da história de Walter Benjamin.

Todos que já se dispuseram a ler os textos do filósofo alemão Walter Benjamin, especialmente os seus grandes ensaios, sabem bem das dificuldades que eles apresentam, mesmo depois de leituras detidas. Não obstante isso, algumas de suas idéias centrais ficam ali claramente expostas. Penso, especialmente, nos ensaios dos anos de 1930, já fortemente influenciados pelos diálogos que seu autor vinha mantendo com Bertolt Brecht.

Tal aproximação com o dramaturgo alemão acentuou-se quando Benjamin passou a ser recebido por ele em sua residência na Dinamarca, por longas temporadas. As crescentes dificuldades materiais que foram se impondo ao judeu-alemão Walter Benjamin, desde a tomada de poder por Hitler em 1933, certamente contribuiu para uma aproximação maior entre os dois amigos, especialmente no que diz respeito às idéias de Marx, que em Brecht já estavam muito presentes. É justamente em função desse ideário marxista, certamente filtrado por um pensamento tão original como o de Benjamin, que se torna necessário chamar a atenção para um novo modo de exposição utilizado pelo autor de Origem do drama barroco alemão. Se nesta obra, concluída em 1925, e representante do que muitos chamam de sua fase mais idealista, a linguagem se mostrava num grau de densidade bastante elevado, frequentemente beirando o hermetismo, cabe dizer que nos seus textos da década de 1930, ainda que a densidade típica de um texto benjaminiano esteja presente na maioria dos seus textos mais importantes, o hermetismo sofrerá uma sensível diminuição. Isso se deu, certamente, em função da crescente perspectiva política que seus textos passaram a adquirir. Indo ao ponto que interessa aqui: suas posições de 
esquerda, independente de uma maior ou menor dificuldade imposta pelos textos, eram, ou deveriam ser, inequívocas. No entanto, como costumo dizer, dada a essa conhecida densidade dos principais ensaios de Benjamin, não foi incomum que certas posições políticas do crítico alemão acabassem como que soterradas sob uma camada de erudição de cunho nitidamente conservador. Em especial num ambiente acadêmico como o nosso, que vinha de uma despolitização muito grande ocorrida no final do século XX. Tal despolitização, como se sabe, era fruto, em larga medida, das desilusões trazidas com o esfacelamento de um projeto efetivamente socialista, desilusões essas a que se seguiram aqueles anos de 1990, encharcados de idéias neoliberais. Tal configuração parecia sinalizar que estávamos nos dirigindo para um glorioso "fim da história" 23 , sob uma espécie de "Pax Americana" que, evidentemente, não se sustentava, mesmo que nosso olhar se detivesse na própria década de 1990, bastando pensar na Guerra do Iraque. Da mesma forma, cerca de dez anos depois iríamos nos deparar com o ataque às Torres Gêmeas, quando fomos introduzidos de chofre no novo século, que de "Pax Americana" não tem nada, muito pelo contrário.

2.

Essas observações iniciais servem apenas para contextualizar rapidamente o nosso momento de leitura e de investigação em torno a um dos conceitos centrais de Benjamin e, sem dúvida, bastante atual. Sabemos que a recepção mais abrangente de sua obra inicia-se nos turbulentos anos de 1960, em especial no ambiente das revoltas estudantis de maio de 1968, que se espalharam pelo mundo a partir da Paris revolucionária, a última revolução, a rigor, de âmbito internacional. De lá para cá o conhecimento de suas ideias não parou de crescer, e gradativamente fomos estabelecendo contato com seus principais conceitos, tais como os de aura, alegoria e experiência, para citar os mais divulgados desde então. Nos últimos anos, e certamente não por acaso,

${ }^{23}$ A referência maior aqui, sem dúvida, vem a ser o ensaio "The end of history", publicado pelo norte-americano Francis Fukuyama em 1989. A partir dele outros autores saíram em defesa de ideias mais ou menos correlatas as suas, que, entre outras coisas, contribuiu para um descrédito de toda a tradição marxista, especialmente durante os anos de 1990. Certamente foram muito influenciados, também, pela queda do muro de Berlim e pela desintegração da antiga União Soviética. 
como veremos, tem-se lembrado recorrentemente do seu conceito de imagem dialética. O que proponho aqui é expor algumas reflexões, de caráter introdutório, direcionadas para todos aqueles que se dispõem a debater e a incorporar tal conceito em suas investigações acadêmicas ou nas suas intervenções em área propriamente política. Ao mesmo tempo, aproveito para, particularmente, "afinar" o entendimento desse conceito, no intuito de utilizá-lo e aclimatá-lo à nossa realidade e ao nosso Jeztzeit, para já irmos utilizando a linguagem benjaminiana. Essa expressão, "tempo do agora", uma das traduções para o português dessa expressão alemã utilizada por Benjamin, vem a ser decisiva para o entendimento do conceito de imagem dialética, e a ela retornarei em seguida. Antes disso uma breve introdução geral ao conceito aqui em questão.

3.

As chamadas teses sobre o conceito de história são, de fato, menos teses (...) que alegorias ou imagens dialéticas. Alegorias da dialética, Katia Muricy

Em primeiro lugar, cabe dizer que o conceito de imagem dialética organiza e constitui todo o pensamento benjaminiano em relação à história. ${ }^{24}$ Costuma-se falar em conceito benjaminiano da história, o que não é propriamente correto. Que ele elabore um conceito de história seria, talvez, uma expressão mais adequada. A história, como bem sabemos, vem a ser um campo disciplinar, e não propriamente um conceito. O que temos, portanto, é uma concepção de história muito particular do filósofo alemão, que tem na imagem dialética o seu centro. Mais de um comentador de sua obra já apontou que a ideia de história que ele desenvolveria mais tarde já apontava em germe num dos seus primeiros textos importantes, escrito ainda na sua juventude. Refiro-me ao pequeno ensaio chamado "A vida dos estudantes", de 1915, onde se insinuava claramente uma concepção de história contrária àquela vigente, seja a chamada história positivista, seja a historicista, ambas dominantes na época.

24 "É consenso na literatura sobre Benjamin considerar como categoria central de sua historiografia a imagem dialética”. BOLLE, Willi. Fisiognomia da metrópole moderna. São Paulo:Edusp, 1994, p. 61. 
Há uma concepção da história que, confiando na eternidade do tempo, só distingue o ritmo dos homens e das épocas que correm rápida ou lentamente na esteira do progresso. A isso corresponde a ausência de nexo, a falta de precisão e de rigor que ela coloca em relação ao presente. As considerações que se seguem visam, porém, a um determinado estado de coisas na qual a história repousa concentrada em um foco, tal como desde sempre nas imagens utópicas dos pensadores (BENJAMIN, 1986, p. 151).

Desse texto inicial até as suas famosas "Teses sobre a filosofia da história" 25 , Benjamin iria elaborar o que estamos chamando de sua concepção da história. Sabemos que as "teses" sobre a história deveriam servir como uma espécie de capítulo introdutório a sua opus magnum, sua obra maior, o Passagen-Werk, ou o Livro das Passagens, que ficou, como sabemos, inacabado. Esse capítulo sairia, fundamentalmente, do já referido Arquivo N, que se compõe de cerca de 30 páginas reunindo fragmentos de textos alheios e anotações de próprio punho que embasariam o que deveria ser uma epistemologia do Passagen-Werk. ${ }^{26}$ No centro desse capítulo, como já dito, estaria o conceito de imagem dialética.

Quais as ideias fundamentais de Benjamin em relação à história, no momento em que conclui o seu percurso, ou seja, em 1940, quando redige as "teses", poucos meses antes do seu trágico fim em Port-Bou? Contrariando fortemente a concepção positivista e mesmo a historicista, Benjamin irá advogar que nada do que aconteceu historicamente pode ser dado por encerrado. Advogava, portanto, o que depois ficaria conhecido como uma "história aberta", ou mais precisamente, "em aberto". Ora, essa idéia contrariava, e ainda contraria, concepções que tendem a ver os fatos históricos como algo fixado para sempre nos arquivos da humanidade. É importante destacar aqui que não se trata simplesmente de se olhar para os fatos históricos com uma perspectiva "diferente",

\footnotetext{
25 Sobre o conceito da história. In: Magia e técnica, arte e política. 2a Ed. São Paulo:Brasiliense, 1986. Obras Escolhidas.

26 "No livro sobre as Passagens, na seção N, é apresentada a epistemologia que sustenta as teses”. MURICY, Katia. Alegorias da dialética: imagem e pensamento em Walter Benjamin. Rio de Janeiro:Relume Dumará, 1999. p. 218.
} 
adotando outra "perspectiva". Nesse sentido, o historicismo já havia superado a história positivista, que acreditava que a função fundamental do historiador seria a de recuperar o que "efetivamente aconteceu", segundo a célebre formulação de Ranke, historiador alemão do século XIX. Não se tratava, segundo Benjamin, da possibilidade de se olhar para $\mathrm{o}$ acontecido de maneira diversa, mesmo que fosse à maneira historicista, mas de negar que fosse possível estabelecer e se fixar o acontecido, porque a questão verdadeira era: como fixar o acontecido, com que meios humanos arquivar uma multidão de fatos ocorridos. E caso seja feita uma seleção desses fatos, como assegurar que tal seleção contenha a "verdade histórica" de uma vez por todas? A lembrança de Borges aqui pode nos ajudar a entender melhor essa concepção benjaminiana de história.

4.

Segundo um conhecido texto do autor argentino, "Sobre el rigor en la ciencia" (1974) imaginou-se realizar um mapa tão perfeito, mas tão perfeito, que acabaria se identificando ponto a ponto com o próprio território que pretendia mapear, o que acaba levando, evidentemente, a uma total irrelevância do referido mapa. Borges pensava aí a questão da representação, na esteira de um dos a priori de Kant, o "espaço".

... En aquel Imperio, el Arte de la Cartografía logró tal Perfección que el mapa de una sola Provincia ocupaba toda una Ciudad, y el mapa del império, toda una Provincia. Con el tiempo, esos Mapas Desmesurados no satisfacieron y los Colegios de Cartógrafos levantaron un Mapa del Imperio, que tenía el tamaño del Imperio y coin cidía puntualmente con el. [...] (BORGES, 1974, p. 847)

Mas seria num segundo texto, desenvolvido agora no âmbito do outro a priori kantiano, ou seja, o tempo, que Borges formularia uma reflexão que me interessa particularmente para pensar a questão da história em Benjamin. Refiro-me ao conto "Funes, el memorioso", cujo princípio fundamental guarda semelhanças com a parábola citada anteriormente. Nele, o narrador nos dá alguns exemplos da prodigiosa memória de Funes:

${ }^{27}$ A pequena parábola foi publicada pela primeira vez em uma revista de Buenos Aires, em 1946, e mais tarde veio a fazer parte do livro El hacedor (1960). 
Nosotros, de un vistazo, percibimos três copas en una mesa; Funes, todos los vástagos y racimos y frutos que comprende una parra. Sabía las formas de las nubes australes del amanecer del treinta de abril de mil ochocientos ochenta y dos y podía compararlas en el recuerdo con las vetas de un libro en pasta española que solo había mirado una vez (...) Podía reconstruir todos los sueños, todos los entresueños. Dos o tres veces había reconstruido un día entero; no había dudado nunca, pero cada reconstrucción había requerido un día entero. (BORGES, 1974, p. 488) ${ }^{28}$

A extraordinária memória do protagonista acaba se constituindo para ele em algo totalmente inútil. Mais ainda, trata-se de uma qualidade bastante prejudicial, na verdade massacrante para a sua vida cotidiana, já que não consegue se esquecer de nada, armazenando tudo que sua percepção detecta na realidade. Tal como no texto anterior, Borges retoma a questão da representação, e da necessária seleção a que ela obriga o sujeito, que precisa, necessariamente, selecionar os dados da realidade. Lendo esses dois textos de Borges somos diretamente remetidos a uma expressão por ele mesmo utilizada em vários momentos de sua vasta obra, incluindo aí as muitas entrevistas que deu. Borges se referia à realidade, ao mundo, como sendo algo "demasiado". Para o que nos interessa nesse momento, cabe sublinhar que a concepção de história em Benjamin, sem nunca ter lido Borges, seguia por caminhos semelhantes, no sentido de chamar a atenção para o fato de que o que ocorreu no passado compõe-se de acontecimentos em um número inabarcável, em termos humanos. Portanto, nenhuma historiografia poderia dar conta de tudo o que aconteceu. Seguindo por esse caminho, o historicismo, corrente dominante nas últimas décadas do século XIX e primeiras do século XX, receberia um ataque frontal em mais de uma das teses de Benjamin. E um dos mais difundidos corolários dessa concepção historiográfica contestada pelo filósofo alemão, qual seja, a possibilidade de uma verdadeira História Universal, aparece então como algo absolutamente ilusório. Isso porque a história, como se sabe hoje, é uma construção humana, demasiado humana. Cabe destacar, no entanto, a

${ }^{28}$ O referido conto foi publicado pela primeira vez no jornal La Nación, de Buenos Aires, e mais tarde foi incluído na obra Ficciones (1944). 
perspectiva política introduzida por Benjamin a respeito dessas questões de base metafísica, muito bem expostas e problematizadas por Borges. Falando de forma mais clara, o filósofo alemão tira consequências que passaram ao largo das reflexões do autor argentino a respeito do tempo e da memória, o que seria, aliás, de se esperar. Em oposição ao conhecido idealismo de Borges, o que encontramos em Benjamin é uma visão materialista e dialética do tempo, da história e da memória. As consequências disso não são pequenas. Voltemos, pois, às "teses" benjaminianas.

5.

Comecemos transcrevendo um trecho da 17 a Tese. Diz Benjamin:

O historicismo culmina legitimamente na história universal. Em seu método, a historiografia materialista se distancia dela talvez mais radicalmente do que qualquer outra. A história universal não tem armação teórica. Seu procedimento é aditivo. Ela utiliza a massa dos fatos, para com elas preencher o tempo homogêneo e vazio. Ao contrário, a historiografia marxista tem em sua base um princípio construtivo (1986, p. 231).

Esse "procedimento aditivo" atribuído por Benjamin ao historicismo transforma seus adeptos em figuras lembram Funes, configurando o tempo histórico em algo "vazio e homogêneo", como se o tempo histórico fosse o desfiar de um rosário. Algo absolutamente uniforme, onde uma conta sucede a outra, ininterruptamente, sem saltos. Já na $5^{\text {a }}$ Tese Benjamin contrapunha a concepção historiográfica materialista ao um historicismo, como afirmou antes, destituído de "armação teórica", que serviu e continua servindo ao que chamamos hoje de história oficial, sempre propícia aos poderosos do momento.

A verdadeira imagem do passado perpassa, veloz. O passado só se deixa fixar, como imagem que relampeja irreversivelmente, no momento em que é reconhecido. "A verdade nunca nos escapará" - essa frase de Gottfried Keller caracteriza o ponto exato em que o historicismo se separa do materialismo histórico. Pois irrecuperável é cada 
imagem do passado que se dirige ao presente, sem que esse presente se sinta visado por ela (BENJAMIN, 1986, 224).

Dessas palavras de Benjamin, destaco aqui duas palavras que teremos que tratar, mesmo que sucintamente, já que apontam para o essencial do conceito de imagem dialética. A primeira delas é a palavra "imagem", a segunda a expressão "materialismo dialético". Quanto à imagem, cabe dizer que o pensamento de Benjamin, contrariando em grande medida os procedimentos canônicos da área filosófica, em especial se pensarmos na época histórica em que redige suas "teses", não irá privilegiar o "conceito", mas a "imagem". Seu pensamento, naqueles momentos mais cruciais, constitui-se, como se diz hoje, por imagens. Por isso que quando alguém afirma que as reflexões de Benjamin percorrem um caminho "poético", não está de todo errado, embora tenhamos que dar o devido desconto a essa ideia. Esse pensar por imagens já estava muito presente em sua obra, pelo menos desde Origem do drama barroco alemão, publicado em 1925, dois anos antes de dar início ao PassagenWerk. Não por acaso, uma das três partes das Obras escolhidas II, textos reunidos de Benjamin pela editora Brasiliense, chama-se justamente "Imagens de pensamento", um termo que ele próprio utilizava para caracterizar seu modus operandi.

Quanto à dialética, evidentemente, esclarece a filiação de Benjamin ao pensamento de esquerda, particularmente o de Marx, embora se distancie dele em vários momentos. Seja como for, quando Benjamin se refere nas "teses", especialmente, ao historiador materialista, trata-se da perspectiva historiográfica que ele defende, naturalmente, ou seja, a do materialismo dialético. E mais do que isso, seja no Arquivo N, seja nas "teses", é visível que ele desenvolve um verdadeiro programa pedagógico para um historiador que se queira revolucionário. Chegamos aqui a uma terceira palavra importante quando se deseja pensar o conceito de imagem dialética. Trata-se da ideia de "revolução". Como estamos vivendo um momento histórico cada vez mais polarizado do ponto de vista político, a ideia de revolução deixa de trazer em si aquela conotação quase que alucinatória que chegou a ter naqueles anos de 1990, incluindo aí certos ambientes de esquerda. Embora introduza nessa ideia de revolução elementos do judaísmo que não estavam presentes nas concepções clássicas à esquerda, às vezes até as contrariando, Benjamin irá até o fim apostando numa revolução, e para a sua efetiva realização ele buscava contribuir, a partir do seu ponto de observação e de trabalho. 
Esse período mais militante de Benjamin, sem dúvida nenhuma, teria início com o seu exílio parisiense, a partir de 1933, quando ele e muitos outros pensadores e artistas alemães se viram obrigados a fugir das perseguições nazistas, e ele se encontrou, mais do que nunca, numa situação bastante precária, principalmente do ponto de vista econômico. $\mathrm{E}$, não por acaso, esse é o período em que mais vai estreitar suas relações com Brecht, conforme eu já havia sublinhado. ${ }^{29}$

Tanto Benjamin como Brecht, ao se colocarem a serviço dos oprimidos da história, aos "de baixo", como se diz hoje, contribuíram para um revigoramento do materialismo dialético naquele período. No contexto de uma conversa com seu amigo Ernst Bloch, quando expunha a ele suas principais ideias sobre o Passagen-Werk, e toda a recuperação histórica do século XIX que pretendia fazer, para melhor entender o seu século XX, em especial aqueles duros anos de 1930, Bloch assim se refere ao seu livro: "A história mostra seu distintivo da Scotland Yard". A formulação de Ernst Bloch, a princípio um pouco estranha, explica maravilhosamente bem muitas das preocupações de Benjamin, assim como, sinteticamente, sua visão histórica e principalmente política do mundo moderno. Como esclarece um comentarista da obra benjaminiana, ao interpretar a imagem de Bloch, "o historiador aparece aí no papel de detetive, preste a investigar os rastros de um crime, que são os feitos da burguesia” (BOLLE, 1994, nota 3. p. 62).

Talvez estejamos num momento histórico, neste sentido, muito próximo aos anos de 1930, em que não é mais possível, ou não tem mais cabimento esconder os muitos crimes da burguesia, que são, nesta altura do jogo, mais do que notórios. Leia-se: deste jogo chamado, em grandes linhas, "a Modernidade", tal como Baudelaire, e o próprio Benjamin, a definiram. Burguesia aqui, portanto, vista no contexto dos últimos duzentos anos e trinta anos, aproximadamente, em especial a partir da Revolução Francesa de 1789, seguida pela propriamente chamada Revolução Burguesa de 1830, seguida pelo massacre da classe operária que irá ocorrer na de 1848, que por sua vez prepara o Segundo Reinado, sob o comando autoritário de Napoleão III, o igual massacre da Comuna de 1871, os conflitos imperiais que levaram à Primeira Guerra de 1814, sua continuação com a Segunda Guerra, que, ao dar fim aos pavorosos campos de concentração, deu fim, também, em segundos, a Hiroxima e

${ }^{29}$ Ver a respeito WIZISLA, Erdmut. Benjamin e Brecht. História de uma amizade. São Paulo:Edusp, 2013. 
Nagazaki, com a igualmente pavorosa bomba atômica, e, por fim, o verdadeiro rosário de guerras durante toda a segunda metade do século $\mathrm{XX}$ até hoje. Crimes contra a humanidade em grande escala, sem nenhuma dúvida, e que continuam a acontecer, sob o beneplácito e a legitimação das democracias ocidentais e, agora, internacionais, que reúnem suas lideranças regularmente para pautarem a história contemporânea.

Livre-atiradores, tanto Benjamin quanto Brecht, não tinham nenhum beneplácito com os horrores que iam constatando naquele período histórico, e que acabaram levando à grande conflagração em 1939. Certamente hoje, se continuassem seguindo as idéias que desenvolveram ao longo dos anos de 1920 e 1930, não teriam o menor beneplácito com os horrores contemporâneos. E aqui chegamos a uma das características mais importantes da imagem dialética benjaminiana, e que diz respeito ao caráter de "urgência" para o qual ela sempre deve se colocar a serviço, urgência essa advinda de um "perigo" iminente. Voltamos assim àquele conceito posto no início, o Jeztzeit, o "tempo de agora". Trata-se de o historiador materialista, detectado esse "perigo", estabelecida a "urgência" de reagir a ele, olhar para o passado como que por um telescópio e, utilizando toda a sua argúcia, apanhar dessa "montanha de acontecimentos" ${ }^{30}$, como vimos acima, aquele ou aqueles que se identifiquem plenamente com o momento presente, e que sirvam como uma espécie de "modelo" ou "inspiração" para enfrentar esse perigo. É nesse momento que se constitui o que Benjamin chama de uma imagem dialética, uma fusão perfeita de passado e presente, formando uma determinada constelação. "Trata-se de indicar o lugar preciso no presente, ao qual a minha construção histórica vai se referir como ao seu ponto de fuga" (BENJAMIN, 2006, p. 69). Benjamin fornece um exemplo bem claro na $14^{\text {a }}$ Tese:

A história é objeto de uma construção cujo lugar não é o tempo homogêneo e vazio, mas um tempo saturado de “agoras". Assim a Roma antiga era para Robespierre um

30 Cabe lembrar aqui a sua já famosa 9a Tese, conhecida como a do "anjo da História", especialmente no trecho em que lemos: "Seu rosto [do anjo] está dirigido para o passado. Onde nós vemos uma cadeia de acontecimentos, ele vê uma catástrofe única, que acumula incansavelmente ruína sobre ruína e as dispersa a nossos pés.” Cf. BENJAMIN, Walter. Op. cit. nota 9. p. 226. 
passado carregado de "ágoras", que ele fez explodir do continuum da história. A Revolução Francesa se via como uma Roma ressurreta. Ela citava a Roma antiga como a moda cita um vestuário antigo. A moda tem um faro para o atual, onde quer que ele esteja na folhagem de antigamente. Ela é um salto de tigre em direção ao passado. Somente, ele se dá numa arena comandada pela classe dominante. $\mathrm{O}$ mesmo salto, sob o livre céu da história, é o salto dialético da Revolução, como o concebeu Marx (1986, p. 229-230).

A ideia de salto aqui é fundamental, porque uma das concepções centrais de Benjamin em relação ao tempo histórico é que ele deve ser visto de forma descontínua, sem respeitar linearidades, causalidades, como era próprio das historiografias oficiais. Ao contrário, é justamente pelos saltos, pela instalação de um novo tempo, que pule fora de uma espécie de "dormência" do tempo histórico "oficial", e que segundo ele só favorecia aos dominantes de sempre, que seria possível aos revolucionários estabelecer uma nova sociedade. A conhecida expressão "tempo vazio e homogêneo" diz respeito exatamente a essa situação. Trata-se aqui de uma constelação simples, de apenas duas estrelas. Normalmente Benjamin trabalha com constelações mais numerosas e, portanto, com imagens dialéticas mais complexas. Quando ele pensa as Passagens ou Galerias Parisienses - precursoras de nossos Shopping Centers - como que sintetizando em um tipo de construção arquitetônica a história social do capitalismo moderno, certamente que aí se constitui uma imagem dialética muito mais complexa. Na verdade, deveríamos falar aqui não em imagem, mas em imagens dialéticas. A Passagem do século XIX ela mesma pode constituir uma imagem dialética a partir de uma vinculação que se faça a um moderno Shopping Center, mas no seu interior poderão ser estabelecidas muitas outras imagens dialéticas particulares, em especial a partir de um fato histórico, econômico e cultural que mudaria para sempre a sociedade humana: a instalação da mercadoria no coração da vida em sociedade. ${ }^{31}$ Neste sentido, sim,

\footnotetext{
${ }^{31}$ Penso aqui, claro, a partir do conhecido conceito "fetichismo da mercadoria", desenvolvido por Marx em O capital.
} 
podemos ver o "capitalismo como religião" ${ }^{32}$, título de um ensaio de Benjamin, e claro que o seu templo, hoje, vem a ser o referido Shopping Center.

Esses dois exemplos que dei de imagem dialética, um de caráter particularmente político, outro mais propriamente social e cultural, obviamente, estão intrinsecamente ligados, como se fossem faces de uma mesma moeda. O domínio político daquela burguesia evidentemente reproduz, ou melhor, é fruto, de uma dominação econômica e, por sua vez, cultural no amplo sentido da palavra. Pôr um fim a essa dominação, é o que Benjamin almeja. Mas é importante, antes de concluirmos essa rápida introdução ao conceito de imagem dialética, lembrarmos que, ao contrário de Marx e toda uma tradição marxista, Benjamin não reserva sua simpatia para uma única classe, aquela que, segundo Marx, levaria a humanidade à sua libertação, ou seja, a classe operária. Embora eventualmente possa se referir, ortodoxamente, à classe operária, no mais das vezes Benjamin abraça também o lúmpen - que Marx não via com bons olhos -, abarca o excluído em geral, o pária, o desviante etc ... etc ... enfim, todos aqueles que de um modo ou de outro acabaram "pagando o pato", como se diz na gíria, ao que o mundo moderno se acostumou a chamar de progresso.

Para concluir, um pequeno trecho de uma das maiores especialistas na obra de Benjamin, especialmente o Passagen-Werk, a norteamericana Susan Buck-Morss. Diz ela:

Mas para que o sonho coletivo fosse efetivo no momento revolucionário do presente, ele devia ser interpretado. Assim como, segundo a teoria freudiana, as imagens oníricas dos indivíduos tinham como origem as experiências anteriores da sua história pessoal, as imagens coletivas tinham sua origem na história social prévia. $\mathrm{O}$ objetivo terapêutico era precisamente desenterrar essas origens e mostrar como formavam uma constelação com o presente. $\mathrm{O}$ desejo onírico se fazia consciente, liberando energias psíquicas reprimidas que seriam usadas na tarefa de transformar o desejo de felicidade em um programa revolucionário coletivo. Em verdade, o livro das Passagens

32 BENJAMIN, Walter. O capitalismo como religião. In: O capitalismo como religião. São Paulo:Boitempo, 2013. 
poderia ser lido como psicoterapia coletiva para uma classe revolucionária que estava sofrendo os sintomas da impotência (2005, p. 32).

\section{REFERÊNCIAS}

BENJAMIN, Walter. Passagens. Organização: Willi Bolle. Colaboração: Olgária Chain Féres Matos. São Paulo/Belo Horizonte: Ed.UFMG/Imprensa Oficial do Estado de São Paulo, 2006. Sobre o conceito da história. In: Magia e técnica, arte e política. 2a ed. São Paulo:Brasiliense, 1986. Obras Escolhidas. . O capitalismo como religião. São Paulo: Boitempo, 2013.

A vida dos estudantes. In: Documentos de cultura, documentos de barbárie: escritos escolhidos. Seleção e apresentação: Willi Bolle. São Paulo: Cultrix, 1986.

BOLLE, Willi. Fisiognomia da metrópole moderna. São Paulo: Edusp, 1994.

BORGES, Jorge Luis. Obras completas. Buenos Aires: Emecé Editores, 1974.

BUCK-MORSS, Susan. Walter Benjamin, escritor revolucionário. Buenos Aires: Interzona, 2005.

EILAND, Howard \& McLAUGUIN, Kevin. Translator'Forewords. In: BENJAMIN, Walter. The Arcades Project. Cambridge: Harvard University Press, 1999.

KOTHE, Flávio René. O "Trabalho das Passagens". In: Benjamin $\mathcal{E}$ Adorno: confrontos. São Paulo: Ática, 1978. p. 74-118.

MISSAC, Pierre. Passagens de Walter Benjamin. São Paulo: Iluminuras, 1998.

MURICY, Katia. Imagens dialéticas. In: Alegorias da dialética. Rio de Janeiro: Relume Dumará, 1998. p. 213-234.

ROUANET, Sérgio Paulo. As Passagens de Paris. In: As Razões do Iluminismo. São Paulo: Cia. das Letras, 1987. p. 37-109.

TIEDEMANN, Rolf. Introdução à edição alemã (1982). In: BENJAMIN, Walter. Passagens.Organização: Willi Bolle. Colaboração: Olgária Chain Féres Matos. São Paulo/Belo Horizonte: Ed.UFMG/Imprensa Oficial do Estado de São Paulo, 2006. p. 13-33. 
WOLIN, Richard. Experiénce et materialisme dans le Passagen-Werk de Benjamin. In: WISMANN, Heinz. Walter Benjamin et Paris. Paris:Les Éditions du Cerf, 1986. p.669-685.

WITTE, Bernd. Pasajes parisienses. In: Walter Benjamin. Una biografía. Barcelona: Gedisa, 1990.

WIZISLA, Erdmut. Benjamin e Brecht. História de uma amizade. São Paulo: Edusp, 2013.

Recebido em: 10/01/2018

Aceito em: 17/03/2018 